\title{
Introducing a Sugar Tax, Morally Justifiable? A Debate on the Introduction of the UK Soft Drinks Industry Levy
}

\author{
Charlotte Cliffe
}

The Dickson Poon School of Law, King's College London, UK

Copyright $(2017$ by authors, all rights reserved. Authors agree that this article remains permanently open access under the terms of the Creative Commons Attribution License 4.0 International License

\begin{abstract}
Obesity is increasing throughout the world's population and has been associated with a number of diseases, from cardiovascular disease, diabetes and stroke to cancer and respiratory diseases [1, 2]. In the United Kingdom, an astonishing $62 \%$ of the population was classified as obese or overweight in 2015 [3]. Complications of obesity have resulted in high rates of morbidity and mortality. The announcement last year that the UK government is to impose a tax on sugar is an attempt to tackle this problem; therefore, it is a timely moment to discuss the justifications and ramifications of this, from a moral point of view. This essay will analyse whether obesity can be considered a public health matter and discuss the ethical challenges and criticisms that paternalistic interventions, designed to combat this epidemic may encounter, focusing on the sugar tax.
\end{abstract}

Keywords Public Health, Sugar Tax, Policy, Autonomy

\section{Introduction}

This article will critically debate the announcement the UK is to introduce a soft drinks industry levy, otherwise known as the 'sugar tax'. This is a public health strategy that aims to reduce the impact of obesity on the UK population and it's struggling health service. The impact of obesity on the population includes negative health outcomes such as increased mortality and reduced quality of life, as well as economic implications such as reduced workforce productivity and escalating healthcare costs.[4]

This essay will start reviewing the ethical considerations of public health and the assumption that every individual has a fundamental right to good health. I will then analyse whether obesity can be considered a public health matter. Finally, I will discuss the ethical challenges and criticisms that paternalistic interventions, such as the sugar tax encounter. This essay will consider the public health principle that 'liberty should mean, above all else, the liberation of society from the injustice of preventable disability and early death' [5].

\subsection{Public Health's Responsibility}

Over the last century there have been several attempts at defining Public Health. The World Health Organisation defines public health's primary role as preventing diseases, promoting health and prolonging life among the population as a whole [6]. The aim is to use collective resources to prevent disease and promote and protect health at various levels of collective aggregation of people.' In a practical sense this is achieved through organised measures in the form of 'state governed or state-sponsored interventions.' [7]. The involvement of the government is required to implement public measures with the force of law driving these changes. It is sometimes argued that public health takes a consequentialist approach, in that there is a focus on maximising good outcomes [8]. However, the imposition of these measures introduce 'questions about the scope of privacy' and the restrictions on an individual's autonomy. [8]. Some argue these paternalistic interventions risk individualism, restricting our freedom and autonomy, despite maximising the overall 'good' amongst the population. These concerns will be addressed later, in detail.

\subsection{Health as a Fundamental Right}

For us to understand the responsibility of the government to maximise the public's health, we must consider how we regard health. Is health a fundamental right? Some would argue it is a 'shared human interest in survival, safety and security' $[9,10]$. However, others question the government's involvement in that 'does the state have the right, even the obligation, to try to make its citizens live maximally happy, health and productive lives' [11]. Furthermore, it has been suggested that health is 'only one dimension of human well-being.' [8]. Therefore, we are obliged to consider the other dimensions such as autonomy, respect for individualism and self-determination. Others suggest that public health actually increases all dimensions, including autonomy, as it 'makes possible the liberty to engage in human activity'[12]. If we maximise one's health, we 
increase the potential to live longer, without disability, essentially prolonging one's time for making autonomous decisions, maximising one's overall self-determination.

\subsection{Public Health Ethics}

To justify public health ethics, we assume acceptance of health as a fundamental good. Throughout the literature it is clear there are core principles that public health adheres to, justifying regulation within society. These include:

1. An overall public health benefit.

2. The intervention must be a necessity, based on good evidence.

3. Minimisation of infringement and restrictions on liberty $[9,13]$.

4. Aim to reduce inequalities, improving justice among the population.

5. Ensure there is collective action so that all the public will abide to the regulation [8] as 'all persons are equally responsible for sharing the burdens' [5].

6. An important difference between public health and the rest of bioethics is the aim to benefit the population, as opposed to the individual [13].

\section{Obesity- A Public Health Matter?}

Can we consider obesity a public health problem? Some have described it as an 'irresponsibility of individuals', with resistance particularly from the food industry, insisting obesity is a personal not public health matter [14]. Anomaly (2012), an American Philosopher, asks 'should we consider watching television, eating junk food and becoming obese a public health problem analogous to the spread of typhus or tuberculosis?' He argues that diet and exercise are private matters and is only a public matter if the overall reduction in 'health costs or productivity losses' are sufficient to justify intervention [11].

Anamoly (2012) insists obesity is the same as wearing heels or playing ice hockey; private matters based on personal choices that put one at risk of chronic disease and shortening ones' life; he argues neither are epidemics or concerns of public health. I have three challenges to this claim; firstly, obesity is different because rates have dramatically increased three-fold since 1980 [3]. Therefore, if the definition of epidemic can be understood as 'the incidence of a disease or condition has increased to some level above the baseline for some area of population' [12], this is certainly true for obesity. On researching public opinion on the cause of obesity in the United States, the majority agreed the increasing numbers were a result of food marketing and 'addictions' to food, rather than personal choices [15]. Therefore, my second reason for insisting obesity is different, subsists in the societal and consumerist pressures, as these are more powerful for the consumption of sweet foods, than to play ice hockey or wear heels.

Finally, although these choices appear equal as personal and autonomous decisions; from an evolutionary point of view there is a distinction. It has been hypothesised that we dislike 'bitter' and enjoy 'sugar' due to an evolutionary process that assisted our survival. Tasting bitter foods suggested poison and eating sweet foods prevented starvation, despite this no longer having relevance within our current society [16] and this innate behaviour persists. As a result, we are not hard-wired to play hockey or wear heels but we are hard-wired to eat foods that are sweet tasting. Therefore, the decision is verging towards a subconscious decision, on a different level to our conscious decisions such as, 'Do I wear heels today or shall I play ice hockey?'.

We could question whether this subconscious desire to eat sweet foods, no longer necessary in our society, thwarts our autonomous decisions, preventing a true reflection of an individual's authentic choice. It has also been suggested obesity should be classified as a psychiatric disorder. If individuals with restrictive eating disorders resulting in under-eating, such as anorexia nervosa, are deemed to have reduced autonomy, why are disorders where the pattern causes over-eating, not the same? Additionally, several symptoms are comparable to addictive disorders, suggesting a loss of autonomous control, so perhaps one might question how much of an autonomous decision, one makes towards food, when they are obese? [17].

Taking these points into consideration, obesity is not comparable to wearing heels or playing ice hockey. Moreover, we must also acknowledge the burden of the illness on the population, in terms of cost. Obesity-related illnesses result in rates as high as $7 \%$ of all healthcare costs in the United States and 1-5\% of all costs in Europe with $10 \%$ total loss of productivity due to sick leave or disability [1]. Cost burden is of particular importance in this country, where a publicly funded system pays for all individuals' medical treatment. One would expect reduced hospital admissions, treatments and disability support with an increase in work productivity, if obesity rates are decreased. However, Anamoly (2012) disagrees, stating studies demonstrate obesity shortens lives, reducing costs overall, therefore providing no cost benefit. Others have challenged the truth to this claim, suggesting it is impossible to calculate accurately [12]. Besides, it is hugely concerning that public health would not consider it more important to prolong healthy lives over accepting shorter lives for the sake of saving money. This could present a 'slippery slope' with other conditions more cost effective for the government to let them die. For example, expensive treatments for cancer, would these become futile if it saves money to let one die earlier?

It is important to note that a socio-economic inequality exists with obesity: those in a lower socioeconomic group are associated with a greater body mass [18]. Public health has a vital role in reducing disease inequality throughout our society [9], therefore ignoring obesity would further violate the core principles. Beauchamp (1976) agreed that public health has a duty to promote the sharing of health burdens equally amongst a population. Therefore, the money 
generated from taxing sugary products could be re-invested to further promote good health, such as reducing healthy food costs and increasing exercise schemes, particularly aimed at socioeconomic groups most in need. Surely this is the very essence of public health's role within our society?

\section{Paternalistic Interventions}

The government aids public health to implement services and policies that protect the population's fundamental right to good health. If a new measure involves a 'limitation on the freedom or autonomy of some agent', is done without consent but aims to improve the welfare of the agent, it is classified as paternalistic [19]. Paternalism is categorised into hard and soft. Soft is often described as 'giving unwanted information or foreclosing some options for action.' And hard can be described as 'direct coercion.' [20].

If we translate this to obesity, soft paternalism would be educating the public on all the risks of eating too much sugar, whereas banning all sugar would be considered hard paternalism. Arguments against any paternalistic intervention include the right for an individual to "live the way they live' and any external body, such as the government, should not objectively decide this. [20] It is claimed this is because no one can fully understand another being's wants, desires and reasons for their choices. Furthermore, the ability for 'reflective self evaluation' is unique to us as humans and any restriction on this defies our right as a human [21]. Another concern with paternalism is that an individual's ability to 'self authorship' is crucial for personal fulfilment [22]. Although these arguments are noteworthy, our fundamental right to health also contributes to self-fulfilment and if an introduction of any intervention is inconsequential to one's life choices, such as a sugar tax, this is hardly significant enough to reduce one's self-authorship.

Mill accepted the Harm Principle, which states that one may justify over-riding decisions of another individual, if the intention is to prevent harm to others. It has been suggested that individual's who are obese are 'unfairly burdening their neighbours.' [23]. The costs and burden obesity places on our community, as discussed earlier, is harmful, particularly when the health system is publicly funded. To ensure the principle of justice is honoured there has to be a 'fair distribution of people's opportunities to pursue their good' this could be either 'the food lover's freedom to feast' or the 'overeaters freedom lost through premature mortality and morbidity' [24]. Although individuals may value the restrictions on food choices or the freedom from illness differently, objectively there is a greater reduction of self-authorship overall from obesity-related disabilities, which restrict all life choices. In fact, one could argue that morbidity eventually restricts all freedom to make food decisions, if one is unable to physically proceed to the shops.

We must also consider the impact on children, as they consume a considerable amount of these sugary products. It is frequently documented that childhood obesity is a significant risk factor in developing adult obesity $[25,26]$. Children lack full capacity to make autonomous decisions, therefore ethical concerns over the restrictions of their freedom to eat sugar becomes irrelevant, particularly as the other principles to 'do no harm' and ensure social justice are not age-dependent, thus stronger arguments.

\section{Sugar Tax}

It is important to acknowledge that sugar is not the only cause behind obesity, but it has been widely reported that the excess energy that sugar provides is a leading cause to the development of excess weight, which in turn can put one at risk of developing obesity. [27] If we consider the government's decision to tax sugar, it is perhaps challenging to categorise. It is not hard paternalism, as there is no direct coercion to stop sugar consumption, or soft paternalism, as the intervention is more restricting than gentle education. Perhaps it matches more closely a new concept of paternalism called 'libertarian paternalism'. This has been developed on the basis of behavioural research with an aim to 'steer people's choices in directions that will improve their lives', colloquially named as a 'nudge' [28]. It is a method to influence choices through altering 'people's behaviour in a predictable way, without forbidding any options or significantly changing their economic incentives' (Thaler 2008 p.6), but ultimately the individual has the overall decision. It affects people's behaviour by subtle influences over their psychological decisions. There is conflicting evidence over the effectiveness nudge strategies have as public health strategies.[29] However, a recent systematic review demonstrated that nudge interventions are extremely effective public health strategies in relation to dietary choices.[30]

'Nudge' has been met with resistance; as some have expressed concerns that 'nudges' are just a more 'subtle form of manipulation' $[28,31]$. However, without any form of influence or 'nudge' individuals may not appreciate their decisions 'in an emotionally genuine manner' [32]. In other words, it is not always possible for every individual to have complete awareness of all the dangers and risks of their actions, therefore one must question whether these decisions, without appropriate education or intervention, are always fully informed?

Furthermore, Thaler (2008) has argued that there it is a 'false assumption that almost all people, almost all of the time, make choices that are in their best interest.' [28] As 'individuals do not always act rationally in their own best interests' [33]. Research demonstrates those who smoke, do not always want to smoke and those overweight, do not want to be overweight [28]. Choosing to spend money on sugar may appear as an autonomous decision at the time, but overall may not reflect the true authentic choices an individual fundamentally desires. This may be for a number 
of other reasons, from choosing a path of 'least resistance' to the influences around them or 'not giving full attention to their options' [34]. These powers around us threaten our existence of total autonomy. All our decisions including those to over-eat and under-exercise are a result of societal influences around as we 'cannot escape the myriad of influences that surround us' [33]. In Mexico, Hungary and Finland new taxes have already been implemented, on unhealthy foods, attempting to change these societal influences. The impact on these countries has dramatically decreased the pace of buying unhealthy foods [3]. This suggests our decision to buy unhealthy foods is adaptable, providing more evidence that people adjust to whatever the societal influence at that time.

The sugar tax could be considered unjust on those who are not obese but having to pay more for their sugary items. However, we have stressed the shared responsibility of burden and the purpose of public health to target the whole population, rather than individuals. Besides, a small tax could be considered an insignificant amount for many and would perhaps change one's 'automatic' thinking to allow greater reflection before making any food judgments, protecting those without obesity from other illnesses too, such as diabetes. 'Food prices act as signals for consumers and have an important role in purchasing decisions' [3]. This is the very essence of a 'nudge' [35].

A sugar tax has already been successfully implemented in other countries. In Mexico a tax was introduced two years ago and the results have been positive; there was an estimated drop in consumption of $5.5 \%$ in the first year, followed by $9.7 \%$ decline in consumption over the second year.[36] In the US, a similar tax was implemented in California in 2015, with some evidence to suggest sugary drinks are consumed at a lower rate.[37] The tax has been particularly effective amongst children.[38] However, in both of these countries it is too early to determine the impact on obesity.[39] One must consider other similar interventions imposed on the healthy population in the UK, for example cigarette and alcohol taxes. Evidence suggests these taxes are effective strategies to promote public health strategies, such as stopping smoking.[40]

On average, there are 8,697 deaths from alcohol in the UK and 100,000 deaths a year from smoking related illnesses [41, 42]. In comparison, 70,000 deaths a year are reportedly due to obesity-related illnesses [43]. Therefore, if we accept taxes on cigarettes and alcohol, why is obesity, which has almost eight times the number of yearly deaths, compared to alcohol, any different? Furthermore, those in lower socioeconomic groups have higher rates of obesity and the evidence suggests that obesity and related illnesses will reduce most significantly in this group. Public health has a duty to ensure these health inequalities are minimised.

The money raised from the extra tax in the UK, will be invested in programmes to encourage exercise and promote balance diets in school-age children.[44] Therefore, this money facilitates new initiatives to further promote public good and wellbeing, particularly among an important and vulnerable age group.

One could argue that taxing sugar is not a 'nudge'. Let us imagine a significant increase in tax, making them unaffordable to most. If this was true, that individuals are forced into not buying the products, we could perhaps classify this as hard paternalism. However, one could question whether one can ever be forced into not doing something. It would not be considered true that our society forces me not to buy an expensive Ferrari, simply because I am unable to afford one.

\section{Conclusions}

Despite the challenges that a sugar tax imposes on an individual's free choice, the underlying intention is good. From a deontological stance, one could argue that the ends justify the means. If we consider the double doctrine of effect, the intention here is to promote good health and autonomy to live one's life without the restriction of disability, demonstrating an intentional and consequential good end. Perhaps, therefore, the means, a potentially small restriction upon one's freedom to buy sugary products, is justified. It could also be accepted from a consequentialist viewpoint, in that maximising happiness through prolonged health and the ability to live without the burden or restriction of obesity justifies the intervention, as long as the good outcome is maximised.

If a sugar tax is implemented it has been estimated there will be a considerable reduction of 180,000 cases a year of obesity [45]. This paper has examined the moral justifications of intervening and the government's responsibility to prevent further cases amidst this rising epidemic. Despite the concerns that any intervention compromises an individual's autonomy, we have justified the introduction of a tax from the perspective of public health. Public health's ethical principles, to do no harm, promote wellbeing and minimise health inequalities are all important to balance against the concerns that tax imposes restrictions on an individual's choices. If we reiterate the potential for severe restrictions on freedom as a result of severe disability and a shortened lifespan; surely it is clear that autonomy is more restricted from this, then simply the choice of food, which is heavily influenced by our subconscious desires and societal pressures anyway? Our society surrounds us with information from advertising and cultural pressures, influencing every decision which prevents our ability for total autonomy anyway. Therefore, we must accept that without intervening the government is violating its responsibility to ensure the good of its population; they have a duty to prevent the epidemic from spreading any further and must protect future generations from such a debilitating disease. 


\section{Funding Statement}

Nothing to declare

\section{Acknowledgements}

Thank you to king's College where I am currently studying an MA.

\section{Conflict of Interest}

nil

\section{REFERENCES}

[1] Visscher, T.a.S., J, The public health impact of obesity. Annu Rev Public Health, 2001. 22: p. 355-75.

[2] Carl Lavie, P.M., Timothy Church, Richard Milani, Steven Blair, Obesity and Cardiovascular diseases: implications. journal of american college of cardiology, 2014. 63(14): p. 1345 .

[3] Cornelson, L.a.C., A, Health-related taxes on foods and beverages 20th May 2015. Food Research Collaboration Policy brief, 2015: p. 1-23.

[4] Thomas Lehnert, D.S., Alexander Konnopka, Steffi Riedel-Heller, ,Economic costs of overweight and obeity. Best practice and research clinical endocrinology and metabolism, 2013. 27(2): p. 105.

[5] Beauchamp, D., Public Health as a social justice Inquiry, 1976. 13(101-109).

[6] WHO. Public Health 2016 [cited 2016 1st April].

[7] Upshur, R., What Does Public Health Ethics Tell (Or Not Tell) Us About Intervening in Non-Communicable Diseases? Bioethical Inquiry, 2013. 10: p. 20.

[8] Faden, R.a.S., Sirine, Public Health Ethics. The Stanford Encyclopedia of Philosophy 2010. http://plato.stanford.edu/archives/spr2015/entries/publichealt h-ethics: p. accessed on 09/04/2016.

[9] Klass, N.H., K; Paul, A and Birnbach, K, Ethics and Obesity Prevention: Ethical Considerations in 3 Approaches to Reducing Consumption of Sugar-Sweetened Beverages. American Journal of Public Health, 2014. 104(5): p. 787-796.

[10] Baylis, F.K., N; Sherwin, S, A Relational Account of Public Health Ethics. Public Health Ethics, 2008. 1(3): p. 197.

[11] Anomaly, J., Is obesity a public health problem? Public Health Ethics, 2012. 5(3): p. 216.

[12] Womack, C., Public Health and Obesity: When a Pound of Prevention Really Is Worth an Ounce of Cure. Public Health Ethics, 2012. 5(3): p. 223.

[13] Childress, R.F., Ruth Gaare, Lawrence GOstin, Jeffrey Kahn, Richard Bonnie, Nancy Kass, Anna Mastrioanni, Jonathon
Morena and Phillip Nieburg, Public Health Ethics: Mapping the terrain. Jounral of law, medicine and ethics, 2002. 30: p. $170-178$

[14] Brownell, R.K., David S. Ludwig, Robert C. Post, Rebecca M. Puhl, Marlene B. Schwartz and Walter C. Willett, Personal Responsibility And Obesity: A Constructive Approach To A Controversial Issue. Health Affairs, 2010. 29(3): p. 379-387 (379).

[15] Barry, C.V.L.B., KELLY D. BROWNELL, and MARK SCHLESINGER, Obesity Metaphors: How Beliefs about the Causes of Obesity Affect Support for Public Policy. The Milbank Quarterly, 2009. 87(1): p. 7-47.

[16] Meyers, B.a.B., M.S. , Sweet Taste in Man: A Review. Jounral of Food science, 2008. 73: p. 81-90.

[17] Volkow, N.a.O.B., C, Am J Psychiatry. 164, 2007. 5(707-710).

[18] McLaren, L., Socioeconomic Status and Obesity. Epidemiologic Reviews, 2007. 29: p. 29-48.

[19] Dworkin, G., Paternalism. The Stanford Encyclopedia of Philosophy, 2002

(http://plato.stanford.edu/archives/spr2015/entries/paternalis $\mathrm{m})$.

[20] Holm, S., Obesity interventions and ethics. Obesity reviews, 2007. 8(1): p. 207-210.

[21] Frankfurt, H., Freedom of the Will and the Concept of a person. THe Journal of Philosophy, 1971. 68(1): p. 5-20.

[22] Mill, J.S., On Liberty. Elecbook Classics, 1998, 1859. 1.

[23] Wickler, D., Who should be blamed for being sick? Health Education Quarterly, 1987. 14(1): p. 11-25.

[24] Kneiss, J., Obesity, paternalism and fairness. J Med Ethics, 2015. 41: p. 889-892.

[25] Serdula, M.I., D; Coates, R; Freedman, D; Williamson, D and Byers, T, Do obese children become obese adults? a review of the Literature. Preventative Medicine, 1993. 22: p. 167-177.

[26] M Simmonds, A.L., CG Owen, N Woolacott, Predicting adult obesity from childhood obesity: a systematic review and meta analysis. obesity review, 2016. 17(2): p. 95.

[27] Stanhope, K., Sugar consumption, metabolic disease and obesity: The state of the controversy.. Crit Rev Clin Lab Sci, 2016. 53(1): p. 52.

[28] Thaler, R.a.S.C., Nudge: Improving decisions about health, wealth and happiness. Penguin Book, 2008. Introduction: p. $1-27$.

[29] Heijden, M.K.a.J.V.d., From mechanism to virtue: Evaluating nudge theory. Evaluation, 2015. 21(3): p. 276.

[30] Thomas, A.A.a.S., The efficacy of nudge theory strategies in influencing adult dietary behaviour: a systematic review and meta analysis. BMC public health 2016. 16: p. 676.

[31] Goodwin, T., Why we should reject Nudge. Politics, 2012. 32(2): p. 85-92.

[32] Dworkin, G., Paternalism. The Monist, 1972. 56(1): p. 64-84.

[33] Quigley, M., NUDGING FOR HEALTH: ON PUBLIC POLICY AND DESIGNING CHOICE ARCHITECTURE. 
Medical Law Review, 2013. 21: p. 588-621.

[34] Vallgarda, S., Nudge-A new and better way to improve health? Health Policy, 2012. 104: p. 200-203.

[35] Selinger, E.a.W., K, is There a Right Way to Nudge? The Practice and Ethics of Choice Architecture. Sociology Compass, 2011. 5(10): p. 923-935.

[36] Boseley, S., Mexico's sugar tax leads to fall in sugar consumption for a secon dyar running, in The Guardian. 2017. p. https://www.theguardian.com/society/2017/feb/22/mexico-su gar-tax-lower-consumption-second-year-running.

[37] Boseley, S., First US sugar tax sees soft drinks fall by almost $10 \%$ study shows in Guardian. 2017. p. https://www.theguardian.com/society/2017/apr/18/first-us-su gar-tax-sees-soft-drink-sales-fall-by-almost-10-study-shows.

[38] Steven Gortmaker, M.L., Stephen Resch, Zachary Ward, Angie Cradock, Jessica Barrett, Davene Wright, Kendrin Sonneville, Cost effectivenss of childhood obesity interventions. America Journal of Preventative medicine, 2015. 49(1): p. 192.

[39] Soares, A.A., Putting taxes into the diet equation. Bull world health organ, 2016. 94: p. 239-240.

[40] Pearl Bader, D.B., Roberta Ferrence, Effects of tobacco taxation and pricing on smoking behaviour in high risk populations, a knowledge synthesis. Int J Environ Res Public health, 2011. 8(11): p. 4118

[41] ASH, Smoking statistics Illness and death. ASH FACT SHEET (action on smoking and health), 2015. http://www.ash.org.uk(2)/ p. 1-4.

[42] concern, A., Statistics on alcohol. Alcohol concern, promoting health improving lives, 2016. accessed on 10/04/2016(website: http://www.alcoholconcern.org.uk/healp-and-advice/statistics -on-alcohol).

[43] Boseley, S., Doctors demand a $20 \%$ tax on sugary drinks to fight UK obesity epidemice. the Guardian, 2015. Health section(http:/www.theguardian.com/society/2015/jul13/docto rs-tax-sugary-drinks-uk-obesity-bma): p. Published on Monda y 13 th July 2015.

[44] Gov.uk, Soft Drinks industry levy: 12 things you should know, in GOV.uk, H.R.C. HM Treasury, and Department of Health, Editor. 2016,

https://www.gov.uk/government/news/soft-drinks-industry-le vy-12-things-you-should-know: Gov.uk.

[45] Briggs, A.M., O; Kehlbacher, A; Tiffin, R; Rayner, M; Scarborough, $\mathrm{P}$, Overall and income specific effect on prevalence of overweight and obesity of $20 \%$ sugar sweetened drink tax in UK: econometric and comparative risk assessment modelling study. BMJ, 2013. 347(6189): p. 1-17. 